\title{
Radio Communication and Research in Great Britain.
}

$\mathrm{B}^{\mathrm{Y}}$ what means is it possible to confine the reception of radio signals to certain well-defined localities? The limiting of the radiation from a transmitting station to moderately definite directions is a fait accompli so far as radio signals of short wavelength are concerned, but a full solution of the larger problem is still awaited. If the regulations governing the use of radio apparatus in Great Britain for experimental and research purposes, as set out in the recently issued revised Post Office licenses, were to be taken seriously, it might be imagined that the solution of the problem is quite well known. The futility of attempting to regulate to certain frontier boundaries the transmission and reception of radio signals, as is apparently required by the rule which states that "Messages shall be transmitted only to stations in Great Britain or Northern Ireland," was discussed at some length in the autumn presidential address to the Radio Society of Great Britain which was delivered by Dr. W. H. Eccles at the Institution of Electrical Engineers on September 24. Such attempted restrictions on research work cannot be to the credit of the country or help friendly international relations in any possible way.

The experimental tests which, during the past three years, have been carried out between radio amateur experimenters in almost every civilised country of the globe have undoubtedly fostered a feeling of good fellowship between those workers-a feeling which cannot but be to the good of all the countries concerned. But what, indeed, are foreign amateurs to think of us if in the future we consistently refuse to reply to their signals and ignore all calls addressed to us through a too rigid adherence to the terms of our licenses ?

The official ban on communications with stations outside the limits of "Great Britain and Northern Ireland " is not even lifted in the cases of the British Colonies, but fortunately (since it may encourage British Government officials to a wider outlook in due time) such views are not held by other countries, as is shown by the following message recently sent to the Radio Society from the Canadian Radio Relay League, a large and influential organisation of radio enthusiasts :-

"Please convey our greetings to the Radio Society of Great Britain with congratulations on their achievements. We also congratulate the Transmitter and Relay Section [of the Society] on their wonderful success in the transatlantic tests, and take this opportunity of expressing our desire for a stronger affiliation between Great Britain and the Colonies for the general benefit of amateur radio."

In most countries where experimental radio licenses are granted, the facilities given with the license are much greater than they are in Great Britain, but in view of the pioneer development work that has been carried out by the radio amateur in recent years, it seems scarcely justifiable to attempt to increase the restrictions upon him.

It should be remembered in this connexion that it was the radio amateurs who discovered the valuable properties of short C.W. waves for signalling over long distances. Up to three years ago the commercial companies and most radio engineers thought that the shorter wave-lengths were of no use for long distances, but radio amateurs, particularly in England, France, Canada, and the United States, gradually extended the ranges across which communication could be carried on with these waves until, as a result of the transatlantic tests conducted by the Radio Society of Great Britain and the American Radio Relay League, the incredulous ones looked into the matter. Since those tests the engineers of the great radio companies of the world have been rapidly investigating these short wave transmissions and carrying on with higher powers and on a larger scale the initial experiments. It seems, therefore, undesirable that there should be another bar to research in Great Britain in a field in which the amateurs in particular have already done good work.

P. R. C.

\section{The Biology of the Suez Canal.}

THE Cambridge expedition for the investigation of the intermingling of the Mediterranean and Red Sea organisms in the Suez Canal left England last week in the Orient liner Orcades. The fauna of the Canal, which was opened in $\mathrm{I} 869$, was first studied by Keller in 1882 , a later reinvestigation of the fishes being made by Tillier in Igo3. The organisms of the Red Sea and the Mediterranean are very different from one another, even though these two seas were connected by a narrow strait, approximately along the line of the Canal, in glacial times. The barrier to intermingling at that period would seem to have been fresh water, a considerable Nile mouth opening into the centre of the strait. In the time of the Pharaohs a navigable canal was dug, connecting a branch of the delta with the Gulf of Suez, which then extended about 30 miles farther north. By the time of Cleopatra this canal became impassable, owing to Nile silt, but it was afterwards reopened, being finally closed for strategic reasons by the Caliph Almansur towards the end of the eighth century. French investigations, carried out at. Suez when Napoleon was in occupation of Egypt, showed certain Mediterranean jelly-fish, sea anemones, and other forms which did and do not extend to the south out of the gulf of the same name. These, if they passed by the Canal, must have been able to withstand the fresh water in its centre. The conditions then were the opposite to those of the present day, for the Bitter Lakes have now a salinity of about 77 grams per litre, or about twice the salinity of either of the terminal seas. These Lakes will be intensively studied, while the fauna of the brine pools in the deserts bordering on the Canal will also be examined.

The Suez Canal Company is giving facilities in respect to boats and by the use of its Canal Stations, and it is hoped to carry the investigation to at least two areas on either side of the Lakes. Each will be intensively collected by trawl nets, dredges, and tow-nets of different sorts, while samples of the bottom and its contained fauna will be obtained by means of the Petersen grab. Similar methods will be adopted at each place, so that comparisons will be possible, not only as to the different species found in each, but also to their relative numbers. The animals will probably be those which live in more or less moving sand, and special gear has been devised to secure these. Then there are such swimming forms as fishes and a few crustaceans. Hard bottom for the attachment of sedentary organisms would only seem to be present in a limited area in the Lakes, but there are piles and other artificial erections, and sunken vessels, in places; however, the larvæ of all are practically free living. The problems before the expedition are to ascertain what forms have passed through the Canal zone from the Mediterranean to 